\title{
Early Detection of Lung Cancer Using CT Scan and Bronchoscopy in a High Risk Population
}

\author{
Vijayvel Jayaprakash ${ }^{1,2,3}$, Gregory M. Loewen ${ }^{4}$, Samjot S. Dhillon ${ }^{5}$, Kirsten B. Moysich ${ }^{1,3}$, \\ Martin C. Mahoney ${ }^{3,5}$, Sai Yendamuri ${ }^{6}$, D. Kyle Hogarth ${ }^{7}$, Mary E. Reid ${ }^{1,3,5^{*}}$ \\ ${ }^{1}$ Cancer Prevention and Population Sciences, Roswell Park Cancer Institute, Buffalo, USA; ${ }^{2}$ Department of Dentistry, Roswell Park \\ Cancer Institute, Buffalo, USA; ${ }^{3}$ Department of Social and Preventive Medicine, State University of New York at Buffalo, Buffalo, \\ USA; ${ }^{4}$ Pulmonary Oncology, Sacred Heart Medical Center, Spokane, USA; ${ }^{5}$ Department of Medicine, Roswell Park Cancer Institute, \\ Buffalo, USA; ${ }^{6}$ Department of Thoracic Surgery, Roswell Park Cancer Institute, Buffalo, USA; ${ }^{7}$ Section of Pulmonary and Critical \\ Care Medicine, University of Chicago, Chicago, USA. \\ Email: vijay.jayaprakash@roswellpark.org, gregory.loewen@providence.org, samjot.dhillon@roswellpark.org, \\ kirsten.moysich@roswellpark.org, martin.mahoney@roswellpark.org, sai.yendamuri@roswellpark.org, dhogarth@uchicago.edu, \\ *mary.reid@roswellpark.org
}

Received August $1^{\text {st }}, 2012$; revised August $31^{\text {st }}, 2012$; accepted September $15^{\text {th }}, 2012$

\begin{abstract}
Background: Computed tomography (CT) and bronchoscopy have been shown to improve the detection rates of peripheral and central lung cancers (LC), respectively. However, the performance of the combination of CT and bronchoscopy in detecting LC, in high-risk patients, is not clear. Patients \& Methods: This prospective study included 205 high-risk patients with a history of at least 2 of the following risk factors: 1) heavy smoking; 2) aero-digestive cancer; 3 ) pulmonary asbestosis or; 4) chronic obstructive pulmonary disease. Patients were offered chest X-ray, sputum cytology, conventional white-light followed by autofluorescence bronchoscopy (WL/AFB) and low-dose spiral CT both at baseline and follow-up visits. Results: Seven patients (3.4\%) were diagnosed with LC or carcinoma in-situ (CIS) at baseline: $\mathrm{CT}$ evaluation detected $5 \mathrm{LC} / \mathrm{CIS}$, while WL/AFB evaluation also identified $5 \mathrm{LC} / \mathrm{CIS}, 2$ of which were not detected on CT. Six (85\%) of these baseline lesions were early stage (0/IA). The relative-sensitivity of CT with WL/ AFB was $40 \%$ better than CT alone. By four year follow-up, 20 patients $(9.8 \%)$ were diagnosed with LC/CIS. CT with WL/AFB detected 19 cases (95\%), whereas CT alone detected 15 cases (75\%). Conclusion: Bimodality surveillance with spiral CT and WL/AFB can improve the detection of early stage LCs among high-risk patients.
\end{abstract}

Keywords: Lung Cancer; Screening; Surveillance; CT Scan; Bronchoscopy

\section{Introduction}

Lung cancer (LC) is the most commonly diagnosed malignancy and accounts for about 1.4 million deaths worldwide [1]. The overall 5 -year survival rate for LC is a dismal $15 \%$. Improved 5 year survival is limited only to early stage LC patients [2]. Patients with a stage I-A LC have a better 5-year survival $(>60 \%)$ compared to a stage III/IV patients $(<5 \%)[3,4]$. However, early stage LC is often asymptomatic, resulting in over $75 \%$ of the patients presenting with locally advanced or metastatic disease at the time of diagnosis [2].

Several large studies examined the effectiveness of chest X-ray and sputum cytology as screening tools to detect LCs [5-8]. Due to the lack of success using X-ray and sputum cytology, researchers have used spiral computerized tomography (CT) of the chest [9-11]. Screen-

"Corresponding author. ing studies have demonstrated reduction in LC mortality rates [12]. The recently concluded National Lung Screening Trial (NLST) multi-institutional trial, comparing annual low dose CT with annual chest radiographs, has established the superiority of CT beyond doubt [13-15]. Spiral CT is a sensitive screening tool for peripheral LCs. A significant percentage of non-central cancers are adenocarcinomas or bronchio-alveolar carcinomas, which more often present as nodules or masses that can be visualized on the CT $[4,16]$. However, CT is less sensitive to detecting central endobronchial tumors, which are more often squamous cell carcinoma (SCC). SCC often develop secondary to a progressive transformation from normal bronchial epithelium to endobronchial premalignant lesions like squamous metaplasia, and dysplasia $[4,17,18]$. These pre-malignant lesions (PMLs) and early micro-invasive cancers are often superficial flat lesions and difficult to detect on $\mathrm{CT}$. 
In the early 1990s, Lam et al. presented data regarding early detection of central LC using a novel fluorescence imaging system $[19,20]$. Since then several studies have been published to support the efficiency of auto-fluorescence bronchoscopy (AFB) $[21,22]$. Although the combination of AFB and conventional white light bronchoscopy (WL/AFB) holds promise in the early detection of central bronchogenic carcinoma, it is unlikely to be useful for the detection of peripheral cancers which are beyond the reach of the bronchoscope. Therefore, combined screening with both spiral CT and WL/AFB might help to increase the detection rate of the both central and peripheral LCs.

Traditionally, screening refers to using a test to identify the disease in the general population, who are asymptomatic to the disease in question. Since the prevalence of LC in general population is low, it can result in poor specificity thereby resulting in over diagnosis and high cost [23]. It makes more sense to use these tests as surveillance tools in a selected high-risk population, where the chance of detecting the disease is higher. This LC surveillance study was conducted to: 1) evaluate the efficiency of bimodality surveillance with spiral CT and WL/AFB and 2) to compare the efficiency of the combination of spiral CT and WL/AFB to spiral CT alone and to the combination of X-ray and sputum cytology.

\section{Materials and Methods}

\subsection{Study Population and Eligibility Criteria}

The study included patients who were enrolled in the High-Risk LC Surveillance Cohort at Roswell Park Cancer Institute (RPCI), Buffalo, NY. A detailed description of the patient enrollment and methodology has been published elsewhere [24]. In brief, eligible patients were asymptomatic for LC and had at least 2 of the following risk factors: 1) radiographically documented pulmonary asbestosis or asbestos-related pleural disease; 2) a history of previously treated small cell (limited disease) or non-small-cell LC, laryngeal cancer, or esophageal cancer with a disease free interval of at least 2 years; 3) a cigarette smoking history with at least 20 pack-years in intensity; and/or 4) a history of documented Chronic Obstructive Pulmonary Disease (COPD) with an $\mathrm{FEV}_{1} \leq$ $70 \%$ of predicted. The patients with serious medical illnesses or psychiatric conditions were excluded. Patients were required to provide informed consent and agree to undergo evaluation for LC. This study was approved by the Institutional Review Board at RPCI.

Most of the patients were referred for LC evaluation due to pre-existing lung diseases, asbestos exposure, or follow-up from a previously surgically treated upperaerodigestive cancer. All qualified patients underwent a pre-diagnostic evaluation which included completion of a comprehensive epidemiology questionnaire, medical history and physical examination. Patients underwent spirometry testing, chest X-ray, sputum cytology (either spontaneous or induced), non-enhanced low-dose spiral CT of the chest, and conventional WL/AF bronchoscopy with biopsy of any abnormal areas.

\subsection{Chest $X-$ Ray}

A Thoravision PA and Lateral standard chest radiograph (X-ray, Philips Medical Systems NA, WA, USA) was performed and read by experienced board certified radiologists at RPCI. Any asbestos related pleural disease, lung nodules or masses were identified and size and description noted. This information was abstracted and entered into a detailed database.

\subsection{Sputum Cytology}

In the initial half of the study, the patients were advised to collect early morning sputum for 3 consecutive mornings before their visit to the hospital. This spontaneous sputum was then pooled and examined. It was later noted that for a high proportion the sputum sample provided was insufficient for cytology. The second half of the study patients underwent induction of sputum with hypertonic saline. Cytology slides prepared from the sputum samples were reviewed by the board certified pathologists at RPCI.

\subsection{Bronchoscopy}

Bronchoscopy was performed under conscious sedation and local anaesthesia using LIFE bronchoscopy system (Xillix Technologies Corp, British Columbia, Canada). All the bronchoscopy procedures were performed by the same pulmonologist (GL). Conventional white light bronchoscopy (WL) was performed followed by an autofluorescence bronchoscopy (AFB). A complete examination included inspection of the vocal cords, trachea, main carina, and orifices of the sub-segmental bronchi to the extent that were visible without causing trauma to the bronchial wall. An effort was made to visualize and photograph up to the third generation bronchi unless contraindicated. The findings on WL/AFB were classified as normal, abnormal or suspicious, based on a previously established grading system [25]. Endobronchial biopsies were obtained from all areas classified as abnormal or suspicious, and a control biopsy was obtained from an area classified as normal under both light sources.

\subsection{Spiral CT Scan}

Non-enhanced spiral CT of the chest was performed and reviewed by RPCI board-certified radiologists. The CT was done within one month of the chest X-ray. Spiral CT 
was performed using a GE Light Speed Plus/QXi machines (GE Healthcare, WI, USA). The images were obtained at $1.25 \mathrm{~mm}$ thickness slices and were filmed as 2.5 $\mathrm{mm}$ slices. Any clinically significant parenchymal pulmonary abnormalities identified by CT was referred for high resolution contrast-enhanced CT of the chest. Nodules were classified as "suspicious" or "non-suspicious" based on their size at baseline, descriptive features (solid/ semi-solid, non-calcified, etc.) or progressive increase in size on subsequent scans. For lesions $<10 \mathrm{~mm}$ follow-up spiral CT was recommended. For lesions $>11 \mathrm{~mm}$, transthoracic needle biopsy or surgical biopsy was recommended.

\subsection{Data Management and Data Analysis}

A database of demographic information from patient questionnaires and the screening test results was maintained. Medical chart review was done to collect any information that was missing from the questionnaire. Data analysis was done using SPSS for Windows, version 14.0 (SPSS Inc., Chicago, IL). Relative sensitivity was calculated by comparing the sensitivities of different testing modalities. A relative sensitivity of greater than 1 would mean an improvement in the sensitivity of one test compared to the other.

\section{Results}

A total of 225 patients were eligible for the study, 205 of whom were consented and completed at least one of the early detection tests. Table 1 presents the demographic characteristics of these patients. The majority of patients enrolled were white males. The average age was 63 years (range: 37 - 83). As expected, most patients reported a history of cigarette use, with $65 \%$ being former smokers and $34 \%$ being current smokers, while only $1 \%$ of the cohort was never smokers. Our cohort included a high percentage of patients with a history of asbestos exposure $(48 \%)$, COPD (81\%) and prior aerodigestive malignancy $(33 \%)$.

Table 2 describes the baseline early detection tests and the results obtained from the 205 patient cohort. Baseline spiral CT was performed on 203 patients yielding a total of 716 nodules among 84 patients (range 1 - 9 nodules), and 20 pulmonary masses among 7 patients (range $1-4$ masses). Baseline X-ray was done on 189 patients and revealed 26 nodules in 11 patients (range 1 - 3 nodules) and 4 pulmonary masses in 3 patients (range $1-2$ masses). Baseline WL/AFB and sputum cytology was completed on 199 and 155 patients, respectively. Baseline WL/AFB examination identified LC/CIS in $2.5 \%$, dysplasia in $(14.6 \%)$ and metaplasia in $(42.3 \%)$. Sputum cytologic

Table 1. Baseline demographic characteristics of 205 patients enrolled in the surveillance study.

\begin{tabular}{|c|c|c|c|}
\hline Patient characteristics & & & Frequency \\
\hline Total no. of patients & & & 205 \\
\hline \multirow[t]{2}{*}{ Gender } & Female & $\mathrm{N}(\%)$ & $62(30.2)$ \\
\hline & Male & $\mathrm{N}(\%)$ & $143(69.8)$ \\
\hline \multirow[t]{3}{*}{ Race } & White & $\mathrm{N}(\%)$ & $200(97.6)$ \\
\hline & Black & $\mathrm{N}(\%)$ & $4(2.0)$ \\
\hline & Other & $\mathrm{N}(\%)$ & $1(0.5)$ \\
\hline \multirow[t]{2}{*}{ Age (years) } & & Mean (SD) & $62.6(8.6)$ \\
\hline & & Range & $37-83$ \\
\hline \multirow[t]{3}{*}{ Smoking Status } & Never & $\mathrm{N}(\%)$ & $1(0.5)$ \\
\hline & Former & $\mathrm{N}(\%)$ & $134(65.4)$ \\
\hline & Current & $\mathrm{N}(\%)$ & $69(33.7)$ \\
\hline \multirow[t]{2}{*}{ Smoking Intensity (Among smokers) } & Pack-years & Mean (SD) & $55.1(27.8)$ \\
\hline & & Range & $3.5-152$ \\
\hline Asbestos exposed ${ }^{*}$ & & $\mathrm{~N}(\%)$ & $99(48.3)$ \\
\hline COPD diagnosed ${ }^{\dagger}$ & & $\mathrm{N}(\%)$ & $165(80.5)$ \\
\hline \multirow[t]{2}{*}{ Aero-digestive cancer history } & One primary cancer & $\mathrm{N}(\%)$ & $58(28.7)$ \\
\hline & More than one primary cancer & $\mathrm{N}(\%)$ & $9(4.0)$ \\
\hline
\end{tabular}

Abbreviations: COPD—Chronic Obstructive Pulmonary Disease; ${ }^{*}$ Either patient reported asbestos exposure or presence of asbestos related disease on x-ray; ${ }^{\dagger}$ Either clinical symptoms of COPD or spirometric values suggesting COPD. 
Table 2. Baseline early detection tests and findings among the $\mathbf{2 0 5}$ patients.

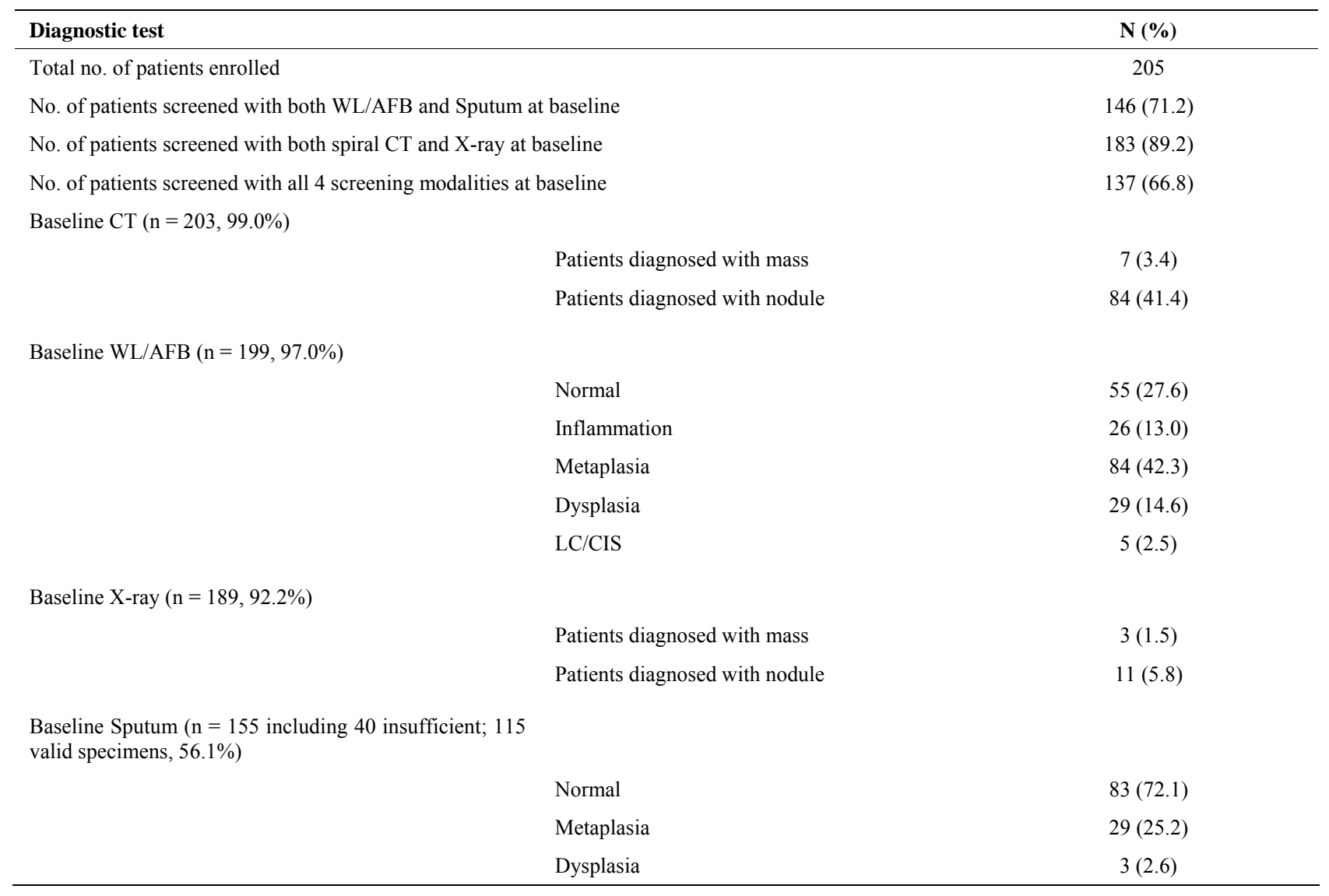

Abbreviations: CIS - Carcinoma-in-situ.

evaluation identified metaplasia (18.7\%) and dysplasia $(1.9 \%)$ among 32 patients.

A total of 20 malignancies LC/CIS were diagnosed among the 205 patients. Tables 3 and $\mathbf{4}$ describe the characteristics and screening test results for the $20 \mathrm{LC} /$ CIS identified in this study. Seven LC/CIS were diagnosed at baseline, 4 within 1 year of baseline screening and 9 on follow up ranging from 2 to 4 years. Together, WL/AFB and CT evaluations detected all baseline cancers. In comparison, only $3 / 7$ cancers were detected on X-ray screening and only $1 / 7$ patients demonstrated atypia on sputum cytology (Table 3). Of the 4 cancers diagnosed within 1 year of enrollment, 1 patient had suspicious changes on the baseline CT, 2 patients had suspicious changes on follow-up CT of the nodules detected at baseline and the other was identified on a follow-up WL/AFB examination. Among the $11 \mathrm{LC} / \mathrm{CIS}$ diagnosed either at baseline or within 1 year of baseline, $8 / 11$ (73\%) were early stage (Stage 0 through II) cancers. Eight incident invasive cancers and 1 CIS were diagnosed on 2 - 4 year follow up on these patients (Table 4). CT evaluation alone detected 7 of these invasive cancers. Bimodal screening with both CT and WL/AFB identified 8/9 LC/CIS.
Overall, 20 LC/CIS (17 invasive cancers and 3 CIS) were diagnosed during this surveillance study. CT detected 15/17 invasive cancers (88\%) and WL/AFB detected $5 / 17$ invasive cancers $(30 \%)$. All of the 3 CIS were identified only on WL/AFB. Additionally, WL/AFB detected a premalignant lesion in 5 additional patients with invasive cancers (30\%). X-ray evaluation detected 4 cancers $(24 \%)$, and sputum cytology showed atypia in 2 patients. Of the $20 \mathrm{LC} / \mathrm{CIS}$ diagnosed on this study, 11/20 $(55 \%)$ were early stage ( 0 through II) cancers. As expected, spiral CT had a better sensitivity when compared to chest X-ray in detecting invasive LC/CIS (relative sensitivity $=3.00)$. Similarly, WL/AFB had a better sensitivity compared to sputum cytology in detecting invasive cancers/PML (relative sensitivity $=2.32$ ).

Table 5 presents the number of invasive LC/CIS detected by spiral CT and WL/AFB. Of the 7 LC/CIS identified at baseline, CT and WL/AFB evaluations detected 5 cancers each. The combination of spiral $\mathrm{CT}$ and $\mathrm{WL} /$ AFB detected all 7 LC/CIS. The sensitivity of the combination of WL/AFB + spiral CT was $40 \%$ better than the sensitivity of spiral CT alone in detecting baseline invasive LC/CIS (relative sensitivity $=1.4$ ). Of all the 20 LC/CIS detected at baseline and on follow-up, spiral CT 
Table 3. Characteristics of the cancers detected at baseline and first year of follow-up by early detection modalities.

\begin{tabular}{|c|c|c|c|c|c|c|c|}
\hline Cancer cell type & $\begin{array}{l}\text { Time of } \\
\text { diagnosis }\end{array}$ & Location & Stage & CT diagnosis & $\begin{array}{l}\text { WL/AFB } \\
\text { diagnosis }\end{array}$ & $\begin{array}{l}\text { X-ray } \\
\text { diagnosis }\end{array}$ & $\begin{array}{l}\text { Sputum } \\
\text { diagnosis }\end{array}$ \\
\hline \multicolumn{8}{|c|}{ Prevalent cancers identified on baseline screening } \\
\hline CIS & At baseline & RML & 0 & Negative & Positive & Negative & Severe dysplasia \\
\hline Small cell & At baseline & RUL & $\begin{array}{l}\text { Limited } \\
\text { disease }\end{array}$ & Positive & Positive & Positive & Negative \\
\hline Carcinoid & At baseline & LUL & 0 & Positive & Positive & Positive & Unavailable \\
\hline Adenocarcinoma & At baseline & RUL & Ia & Positive & Positive & Negative & Unavailable \\
\hline Adenocarcinoma & At baseline & LUL & Ia & Positive & Negative & Negative & Negative \\
\hline Adenocarcinoma & At baseline & LUL & IIIa & Positive & Severe dysplasia & Positive & Negative \\
\hline \multicolumn{8}{|c|}{ Cancers identified within 1 year of baseline screening } \\
\hline Adenocarcinoma & 6 month FU & Bilateral & IV & $\begin{array}{l}\text { Nodule at baseline; } \\
\text { Confirmed positive } \\
\text { on FU }\end{array}$ & $\begin{array}{l}\text { Metaplasia at } \\
\text { baseline }\end{array}$ & Negative & Unavailable \\
\hline Adenocarcinoma & 9 month FU & RUL & Ia & Positive & $\begin{array}{l}\text { Basal cell } \\
\text { hyperplasia \& } \\
\text { dysplasia at } \\
\text { baseline; Positive } \\
\text { on FU }\end{array}$ & $\begin{array}{l}\text { Nodule at } \\
\text { baseline; } \\
\text { Suggested FU } \\
\text { with CT }\end{array}$ & Unavailable \\
\hline Adenocarcinoma & 1 year FU & LLL & Ia & $\begin{array}{l}\text { Nodule at baseline; } \\
\text { Confirmed positive } \\
\text { on FU }\end{array}$ & Negative & Negative & Negative \\
\hline
\end{tabular}

Positive - Suspicious appearance on the test prompting a tissue diagnosis, which was diagnosed as cancer; CIS — Carcinoma-in-situ; BAC — Bronchioloalveolar carcinoma; FU—Follow up; RUL—Right Upper Lobe; RML—Right Middle Lobe; LUL—Left Upper Lobe; LLL—Left Lower Lobe.

Table 4. Characteristics of the incident cancers detected on surveillance of two years and beyond by early detection modality.

\begin{tabular}{|c|c|c|c|c|c|c|c|}
\hline Cancer cell type & $\begin{array}{l}\text { Time of } \\
\text { diagnosis }\end{array}$ & Location & Stage & CT diagnosis & $\begin{array}{l}\text { WL/AFB } \\
\text { diagnosis }\end{array}$ & $\begin{array}{l}\text { X-ray } \\
\text { diagnosis }\end{array}$ & $\begin{array}{l}\text { Sputum } \\
\text { diagnosis }\end{array}$ \\
\hline Squamous cell & 2 year FU & RUL & Ia & $\begin{array}{l}\text { Nodule at baseline; } \\
\text { confirmed positive } \\
\text { on FU }\end{array}$ & $\begin{array}{l}\text { Mild dysplasia } \\
\text { at baseline }\end{array}$ & $\begin{array}{l}\text { Nodule at baseline; } \\
\text { Suggested FU } \\
\text { with CT }\end{array}$ & Metaplasia \\
\hline Small cell & 2 year FU & Left lung & IV & Positive at baseline & Negative & Negative & Negative \\
\hline $\begin{array}{l}\text { Non-small cell } \\
\text { (Neuro-endocrine) }\end{array}$ & 2 year FU & Bilateral & IV & Positive at baseline & Negative & Negative & Negative \\
\hline $\mathrm{BAC}$ & 3 year FU & LUL & IIa & $\begin{array}{l}\text { Nodule at baseline; } \\
\text { Confirmed positive on FU }\end{array}$ & Negative & Negative & Negative \\
\hline Adenocarcinoma & 3 year FU & Bilateral & IV & $\begin{array}{l}\text { Nodule at baseline; } \\
\text { Confirmed positive on FU }\end{array}$ & Negative & Negative & Negative \\
\hline Adenocarcinoma & 3 year FU & Left lung & IV & Negative & Negative & Negative & Unavailable \\
\hline $\mathrm{BAC}$ & 3 year FU & Right lung & IV & $\begin{array}{l}\text { Negative at baseline; } \\
\text { Positive on FU CT }\end{array}$ & $\begin{array}{l}\text { Metaplasia at } \\
\text { baseline }\end{array}$ & Negative & Negative \\
\hline CIS & 4 year FU & RLL & 0 & Negative & $\begin{array}{l}\text { Dysplasia at } \\
\text { baseline; CIS } \\
\text { on FU }\end{array}$ & Negative & Negative \\
\hline Squamous cell & 4 year FU & RUL & $\mathrm{IIIb}$ & $\begin{array}{l}\text { Nodule at baseline; } \\
\text { Confirmed positive on FU }\end{array}$ & $\begin{array}{l}\text { Metaplasia at } \\
\text { baseline }\end{array}$ & Negative & Negative \\
\hline
\end{tabular}

Positive - Suspicious appearance on the test prompting a tissue diagnosis, which was diagnosed as cancer; CIS - Carcinoma-in-situ; BAC - Bronchioloalveolar carcinoma; FU—Follow up; RUL—Right Upper Lobe; RLL—Right Lower Lobe; LUL—Left Upper Lobe. 
Table 5. Efficiency of spiral CT and WL/AFB in detecting prevalent and incident LC/CIS.

\begin{tabular}{|c|c|c|c|c|c|c|}
\hline & \multicolumn{3}{|c|}{ LC/CIS Diagnosed at baseline $(\mathrm{N}=7)$} & \multicolumn{3}{|c|}{ All LC/CIS Diagnosed Either at Baseline or Follow-up $(\mathrm{N}=20)$} \\
\hline & $\begin{array}{l}\text { WL/AFB } \\
\text { positive }^{*}\end{array}$ & $\begin{array}{l}\text { WL/AFB } \\
\text { negative }^{\dagger}\end{array}$ & Total & $\begin{array}{l}\text { WL/AFB } \\
\text { positive }^{*}\end{array}$ & $\begin{array}{l}\text { WL/AFB } \\
\text { negative }^{\dagger}\end{array}$ & Total \\
\hline CT positive $^{*}$ & 3 & 2 & 5 & 4 & 11 & 15 \\
\hline CT negative ${ }^{\dagger}$ & 2 & 0 & 2 & 4 & 1 & 5 \\
\hline \multirow[t]{2}{*}{ Total } & 5 & 2 & 7 & 8 & 12 & 20 \\
\hline & \multicolumn{3}{|c|}{$\begin{array}{ll}\text { - } & \text { Detection rate of spiral } \mathrm{CT}=71 \% \\
\text { - } & \text { Detection rate of } \mathrm{WL} / \mathrm{AFB}=71 \% \\
\text { - } & \text { Retection rate of spiral } \mathrm{CT}+\mathrm{WL} / \mathrm{AFB}=100 \% \\
& \mathrm{CT}+\mathrm{WL} / \mathrm{AFB} \text { to spiral } \mathrm{CT} \text { alone: } 1.4 .\end{array}$} & \multicolumn{3}{|c|}{$\begin{array}{l}\text { - } \text { Detection rate of spiral } \mathrm{CT}=75 \% \\
\text { - } \text { Detection rate of } \mathrm{WL} / \mathrm{AFB}=40 \% \\
\text { - } \text { Detection rate of spiral } \mathrm{CT}+\mathrm{WL} / \mathrm{AFB}=95 \% \\
\text { - Relative sensitivity of the combination of spiral CT+ } \\
\text { WL/AFB to spiral CT alone: } 1.27 \text {. }\end{array}$} \\
\hline
\end{tabular}

*Suspicious appearance prompting either a biopsy, resection or follow-up evaluation; ${ }^{\dagger}$ Non-suspicious appearance.

alone detected $15(75 \%)$ and the combination of spiral $\mathrm{CT}+\mathrm{WL} / \mathrm{AFB}$ detected $19(95 \%)$. The sensitivity of the combination of WL/AFB + spiral CT was $27 \%$ better than the sensitivity of spiral CT alone in detecting baseline and follow-up invasive LC/CIS (relative sensitivity = 1.27).

We also compared the efficiency in detecting PMLs and LCs between bimodality screening with CT and WL/ AFB and bimodality screening with $\mathrm{X}$-ray and sputum cytology (Table 6). CT and WL/AFB detected 19 of the 20 CIS/cancers (95\%), whereas X-ray and sputum cytology together detected only 5/20 CIS/cancers (25\%). The sensitivity of the combination of CT and WL/AFB in diagnosing pre-malignant lesions and cancers improved by almost two and half times relative to X-ray and sputum cytology (relative sensitivity $=2.38$ ).

\section{Discussion}

The optimal lung cancer early detection strategy would be a cost-effective diagnostic test that can be performed on asymptomatic high-risk patients to identify a disease at an earlier stage, when intervention has a good chance of reducing the mortality from the disease. This traditional paradigm does not fit LC early detection due to the lack of tools that are both highly efficient and cost-effective. While X-ray and sputum cytology are less expensive, they are not sensitive early detection tools. Several ongoing and completed studies have established that CT surveillance identifies more lung cancers [12,23, 26,27]. The more recent National Lung Screening Trial was a NCI sponsored large multi-institutional trial (33 centers in US) comparing annual LDCT with annual chest radiographs for 3 years [13-15]. A total of 1060 lung cancers were diagnosed in the LDCT arm and 941 in the chest radiograph arm (645 and 572 per 100,000 person-years respectively). The LDCT group had a $20 \%$ relative reduction in lung-cancer specific mortality $(95 \%$ CI, 6.8 - 26.7; $\mathrm{P}=0.004)$ and $6.7 \%$ reduction in all-cause mortality (95\% CI, $1.2-13.6 ; \mathrm{P}=0.02)$. This was the first randomized trial of lung cancer screening using LDCT that showed a significant decrease in lung cancer-specific mortality.

Similarly, WL/AFB has been shown to be very useful in detecting LC $[21,22,25,28]$. WL/AFB and spiral CT are sensitive tools for detecting central and peripheral LCs, respectively. However, the possibility of false positives and their associated costs could limit their use as screening tools in general asymptotic population. Therefore, there have been few studies evaluating these techniques in the same patient population.

For these tools to be cost-effective, it is necessary to use them in a group of patients in whom the risk of LC is known to be especially high as in our study cohort. This "enriched cohort" explains the high percentage of LC/CIS (3.4\% of the cohort) detected at baseline, compared to several previous studies based on sputum/X-ray and CT scans which detected LC at a rate of $0.1 \%-2.7 \%$ $[5,6,9,11,23,29]$. Also, by incorporating the WL/AFB technique, which is amenable to procurement of tissue biopsies from central airway lesions, our study was able to secure a confirmatory tissue diagnosis on a sub-set of detected lesions. Additionally, on follow-up with the different modalities, 4 cancers ( $2 \%$ of the cohort) were identified in the first year and 8 more LC/CIS (3.9\%) were detected between 2 and 4 years of surveillance.

Overall, 20/205 (9.7\% of the cohort) patients developed a LC/CIS during the duration of the study. Spiral CT screening detected a total of 15 cancers: 2 small cell, 1 carcinoid and 12 non-small cell ( 7 adenocarcinoma, 2 squamous cell and 2 bronchioloalveolar). Our data is consistent with previous studies demonstrating that CT detected cancers are more often adenocarcinomas, usually located in the peripheral lung [9-11,29]. Although spiral CT alone showed a very high sensitivity in detecting cancers compared to other 3 modes of screening, it did not detect any of the 3 CIS lesions noted on LW/AFB. CIS has been shown to be associated with a high rate of progression to invasive cancer [30]. Furthermore, patients diagnosed with CIS and micro-invasive cancers 
Table 6. Efficiency of spiral CT + WL/AFB Compared with X-ray + sputum cytology in detecting prevalent and incident PMLs/cancers.

\begin{tabular}{ccccc}
\hline & & WL/AFB aided biopsy + spiral CT \\
\hline Sputum cytology + X-ray & Metaplasia & Dysplasia & LC/CIS & Total \\
\hline Benign & 36 & 11 & 13 & 60 \\
Metaplasia & 15 & 4 & 0 & 19 \\
Dysplasia & 0 & 2 & 2 & 5 \\
LC/CIS & 0 & 0 & 20 & 8 \\
Total & 51 & 17 & & \\
Relative sensitivity of WL/AFB+ spiral CT compared to sputum cytology + X-ray: 2.38. & & & \\
\hline
\end{tabular}

WL/AFB: White Light and Autofluorescence bronchoscopy; PML Premalignant lesion; CIS: Carcinoma-in-situ.

have a very high 5-year survival rate $(>90 \%)[6,31,32]$. All the 3 CIS diagnosed were detected via WL/AFB. Overall, 15/20 (75\%) LC/CIS were detected on CT evaluation alone. The addition of WL/AFB to spiral CT evaluation identified 19/20 cancers (95\%). Since spiral CT is most effective for identifying nodular lesions and WL/AFB is optimal for detecting superficial, flat and micro invasive lesions, they can be used as complementary techniques to improve the overall LC detection rate. Further, WL/AFB can also be useful in obtaining a tissue diagnosis of suspicious central bronchial lesions detected by CT.

In a previous study that reported on multi-modal early detection, McWilliams et al. examined 561 current and former smokers with sputum cytology, WL/AFB and low-dose CT scans [33]. Baseline screening identified 20 cancers $(3.6 \%$ of the patients), of which $16 / 20(80 \%)$ were identified on CT and 4/20 (20\%) were identified on WL/AFB alone. Similarly, in our study 7 LC/CIS were identified at baseline $(3.4 \%)$. Five $(71 \%)$ of these seven were identified on CT scan and the other two (29\%) were CT occult and detected only on WL/AFB. Another similar finding in both studies was the high percentage of early stage (0/IA) cancers diagnosed at baseline, 16/18 (80\%) in McWilliams et al., compared to 6/7 (85\%) of the baseline cancers in the present study were early stage (0/IA). It would appear that bimodality screening with CT scan and WL/AFB targeted to high risk subjects helps to identify a significant number of prevalent cancers, the majority of which are early stage. Additionally, WL/AFB based biopsy revealed that over $50 \%$ of these high-risk patients demonstrated concurrent metaplastic or dysplastic lesions in their central airway, supporting our position that WL/AFB can identify central invasive cancers and locate endobronchial premalignant lesions.

Several recent reviews have discussed that most of the randomized screening trials using $\mathrm{CT}$ or X-rays have resulted in a reduction in the mortality rate from LC. It must be noted that irrespective of the histologic type of cancer that was detected among our high risk patients (mostly adenocarcinoma), the majority of patients had concurrent premalignant lesions in the central airways. Thus, it is possible that the development of squamous cell carcinomas and adenocarcinomas are concurrent processes within the lung and that the anatomic field at risk might be far wider than what is visualized on CT which might result in incomplete treatment and hence a greater risk of recurrence. $\mathrm{WL} / \mathrm{AFB}$ is able to better delineate central airway fields of change and the combination of this technology with CT screening might help to improve the both detection and therapy.

The current hypothesis was limited to testing the efficacy of the combination of WL/AFB and spiral CT scan in detecting LCs and premalignant lesions and comparing it to X-ray and sputum cytology, in the same group of high risk patients. Therefore, our study did not have a control arm, enrolled limited numbers of subjects and did not follow-up the patients long enough to evaluate the cost per life year or quality-adjusted life years. In spite of that limitation, the current study is one of the first to compare the efficiency of all four early detection tools in the same population.

In summary, our study supports the hypothesis that LC surveillance using complimentary modalities like spiral CT of the chest and WL/AFB can improve the ability to detect early LCs. Higher detection rates can be achieved by limiting surveillance to high-risk patient populations. Future studies should focus more on developing better risk assessment models and biomarkers to identify those patients at high risk in whom these tools will be much more efficient and cost effective.

\section{Funding Support}

This study was supported in part by funding from the Buffalo Oncologic Foundation, the American Cancer Society, Roswell Park Alliance Foundation, the Roswell Park Cancer Institute Center Support Grant (P30CA16056-27) and the Stacey Scott Lung Cancer Registry.

\section{REFERENCES}

[1] A. Jemal, F. Bray, M. M. Center, J. Ferlay, E. Ward and 
D. Forman, "Global Cancer Statistics," CA: A Cancer Journal for Clinicians, Vol. 61, No. 2, 2011, pp. 69-90. doi: $10.3322 /$ caac. 20107

[2] A. Jemal, R. Siegel, J. Xu and E. Ward, "Cancer Statistics, 2010," CA: A Cancer Journal for Clinicians, Vol. 60, No. 5, 2010, pp. 277-300. doi:10.3322/caac.20073

[3] M. D. Brundage, D. Davies and W. J. Mackillop, "Prognostic Factors in Non-Small Cell Lung Cancer: A Decade of Progress," Chest, Vol. 122, No. 3, 2002, pp. 10371057. doi:10.1378/chest.122.3.1037

[4] W. D. Travis, E. Brambilla and H. K. Müller-Hermelink Eds., "Pathology and Genetics: Tumours of the Lung, Pleura, Thymus and Heart," IARC Press, Lyon, 2004.

[5] J. K. Frost, W. C. Ball Jr., M. L. Levin, M. S.Tockman, R. R. Baker, D. Carter, J. C. Eggleston, Y. S. Erozan, P. K. Gupta, N. F. Khouri, et al., "Early Lung Cancer Detection: Results of the Initial (Prevalence) Radiologic and Cytologic Screening in the Johns Hopkins Study," The American Review Respiratory Disease, Vol. 130, No. 4, 1984, pp. 549-554.

[6] M. R. Melamed, B. J. Flehinger, M. B. Zaman, R. T. Heelan, W. A. Perchick and N. Martini, "Screening for Early Lung Cancer. Results of the Memorial Sloan-Kettering Study in New York," Chest, Vol. 86, No. 1, 1984, pp. 4453. doi:10.1378/chest.86.1.44

[7] M. R. Melamed, "Lung Cancer Screening Results in the National Cancer Institute New York Study," Cancer, Vol. 89 , No. 11, 2000, pp. 2356-2362.

doi:10.1002/1097-0142(20001201)89:11+<2356::AID-C NCR8 $>3.0 . \mathrm{CO} ; 2-\mathrm{Z}$

[8] P. M. Marcus, E. J. Bergstralh, R. M. Fagerstrom, D. E. Williams, R. Fontana, W. F. Taylor and P. C. Prorok, "Lung Cancer Mortality in the Mayo Lung Project: Impact of Extended Follow-Up," Journal of the National Cancer Institute, Vol. 92, No. 16, 2000, pp. 1308-1316. doi:10.1093/jnci/92.16.1308

[9] C. I. Henschke, D. I. McCauley, D. F. Yankelevitz, D. P. Naidich, G. McGuinness, O. S. Miettinen, D. M. Libby, M. W. Pasmantier, J. Koizumi, N. K. Altorki, et al., "Early Lung Cancer Action Project: Overall Design and Findings from Baseline Screening," Lancet, Vol. 354, No. 9173, 1999, pp. 99-105.

doi:10.1016/S0140-6736(99)06093-6

[10] S. J. Swensen, J. R. Jett, T. E. Hartman, D. E. Midthun, S. J. Mandrekar, S. L. Hillman, A. M. Sykes, G. L. Aughenbaugh, A. O. Bungum and K. L. Allen, "CT Screening for Lung Cancer: Five-Year Prospective Experience," Radiology, Vol. 235, No. 1, 2005, pp. 259-265. doi:10.1148/radiol.2351041662

[11] S. Sone, S. Takashima, F. Li, Z. Yang, T. Honda, Y. Maruyama, M. Hasegawa, T. Yamanda, K. Kubo, K. Hanamura, et al., "Mass Screening for Lung Cancer with Mobile Spiral Computed Tomography Scanner," Lancet, Vol. 351, No. 9111, 1998, pp. 1242-1245. doi:10.1016/S0140-6736(97)08229-9

[12] C. I. Henschke, P. Boffetta, O. Gorlova, R. Yip, J. O. Delancey and M. Foy, "Assessment of Lung-Cancer Mortality Reduction from CT Screening," Lung Cancer, Vol. 71, No. 3, 2011, pp. 328-332. doi:10.1016/j.lungcan.2010.10.025

[13] D. R. Aberle, C. D. Berg, W. C. Black, T. R. Church, R. M. Fagerstrom, B. Galen, I. F. Gareen, C. Gatsonis, J. Goldin, J. K. Gohagan, et al., "The National Lung Screening Trial: Overview and Study Design," Radiology, Vol. 258, No. 1, 2011, pp. 243-253.

doi:10.1148/radiol.10091808

[14] D. R. Aberle, A. M. Adams, C. D. Berg, J. D. Clapp, K. L. Clingan, I. F. Gareen, D. A. Lynch, P. M. Marcus and P. F. Pinsky, "Baseline Characteristics of Participants in the Randomized National Lung Screening Trial," Journal of the National Cancer Institute, Vol. 102, No. 23, 2010, pp. 1771-1779. doi:10.1093/jnci/djq434

[15] D. R. Aberle, A. M. Adams, C. D. Berg, W. C. Black, J. D. Clapp, R. M. Fagerstrom, I. F. Gareen, C. Gatsonis, P. M. Marcus and J. D. Sicks, "Reduced Lung-Cancer Mortality with Low-Dose Computed Tomographic Screening," New England Journal of Meddicine, Vol. 365, No. 5, 2011, pp. 395-409. doi:10.1056/NEJMoa1102873

[16] T. V. Colby, M. Koss and W. D. Travis, Eds., "Tumors of Lower Respiratory Tract," 3rd Edition, Armed Forces Institute of Pathology, Washington, 1995.

[17] K. M. Kerr, "Pulmonary Preinvasive Neoplasia," Journal of Clinical Pathology, Vol. 54, No. 4, 2001, pp. 257-271. doi:10.1136/jep.54.4.257

[18] A. K. Greenberg, H. Yee and W. M. Rom, "Preneoplastic Lesions of the Lung," Respiratory Research, Vol 3, No. 1, 2002, p. 20. doi: $10.1186 / \mathrm{rr} 170$

[19] J. Hung, S. Lam, J. C. LeRiche and B. Palcic, "Autofluorescence of Normal and Malignant Bronchial Tissue," Lasers Surgery Medicine, Vol. 11, No. 2, 1991, pp. 99105. doi:10.1002/1sm.1900110203

[20] S. Lam, C. MacAulay and B. Palcic, "Detection and Localization of Early Lung Cancer by Imaging Techniques," Chest, Vol. 103, No. 1, 1993, pp. 12S-14S.

[21] E. Edell, S. Lam, H. Pass, Y. E. Miller, T. Sutedja, T. Kennedy, G. Loewen, R. L. Keith and A. Gazdar, "Detection and Localization of Intraepithelial Neoplasia and Invasive Carcinoma Using Fluorescence-Reflectance Bronchoscopy: An International, Multicenter Clinical Trial," Journal of Thoracic Oncology, Vol. 4, No. 1, 2009, pp. 49-54.

[22] F. R. Hirsch, S. A. Prindiville, Y. E. Miller, W. A. Franklin, E. C. Dempsey, J. R. Murphy, P. A. Bunn Jr. and T. C. Kennedy, "Fluorescence versus White-Light Bronchoscopy for Detection of Preneoplastic Lesions: A Randomized Study," Journal of the National Cancer Institute, Vol. 93, No. 18, 2001, pp. 1385-1391. doi:10.1093/jnci/93.18.1385

[23] C. Black, R. de Verteuil, S. Walker, J. Ayres, A. Boland, A. Bagust and N. Waugh, "Population Screening for Lung Cancer Using Computed Tomography, Is There Evidence of Clinical Effectiveness? A Systematic Review of the Literature," Thorax, Vol. 62, No. 2, 2007, pp. 131138. doi:10.1136/thx.2006.064659

[24] G. Loewen, N. Natarajan, D. Tan, E. Nava, D. Klippenstein, M. Mahoney, M. Cummings and M. Reid, "Autofluorescence Bronchoscopy for Lung Cancer Surveillance 
Based on Risk Assessment," Thorax, Vol. 62, No. 4, 2007, pp. 335-340. doi:10.1136/thx.2006.068999

[25] S. Lam, T. Kennedy, M. Unger, Y. E. Miller, D. Gelmont, V. Rusch, B. Gipe, D. Howard, J. C. LeRiche, A. Coldman, et al., "Localization of Bronchial Intraepithelial Neoplastic Lesions by Fluorescence Bronchoscopy," Chest, Vol. 113, No. 3, 1998, pp. 696-702. doi:10.1378/chest.113.3.696

[26] C. I. Henschke, D. I. McCauley, D. F. Yankelevitz, D. P. Naidich, G. McGuinness, O. S. Miettinen, D. Libby, M. Pasmantier, J. Koizumi, N. Altorki, et al., "Early Lung Cancer Action Project: A Summary of the Findings on Baseline Screening," Oncologist, Vol. 6, No. 2, 2001, pp. 147-152. doi:10.1634/theoncologist.6-2-147

[27] S. Sone, F. Li, Z. G. Yang, T. Honda, Y. Maruyama, S. Takashima, M. Hasegawa, S. Kawakami, K. Kubo, M. Haniuda, et al., "Results of Three-Year Mass Screening Programme for Lung Cancer Using Mobile Low-Dose Spiral Computed Tomography Scanner," British Journal of Cancer, Vol. 84, No. 1, 2001, pp. 25-32. doi:10.1054/bjoc.2000.1531

[28] B. Lam, M. P. Wong, S. L. Fung, D. C. Lam, P. C. Wong, T. Y. Mok, F. M. Lam, M. S. Ip, C. G. Ooi and W. K. Lam, "The Clinical Value of Autofluorescence Bronchoscopy for the Diagnosis of Lung Cancer," European Respiratory Journal, Vol. 28, No. 5, 2006, pp. 915-919.

\section{doi:10.1183/09031936.06.00131405}

[29] T. Nawa, T. Nakagawa, S. Kusano, Y. Kawasaki, Y. Sugawara and H. Nakata, "Lung Cancer Screening Using Low-Dose Spiral CT: Results of Baseline and 1-Year Follow-Up Studies," Chest, Vol. 122, No. 1, 2002, pp. 15-20. doi:10.1378/chest.122.1.15

[30] B. J. Venmans, T. J. van Boxem, E. F. Smit, P. E. Postmus and T. G. Sutedja, "Outcome of Bronchial Carcinoma in Situ," Chest, Vol. 117, No. 6, 2000, pp. 1572 1576. doi:10.1378/chest.117.6.1572

[31] D. A. Cortese, P. C. Pairolero, E. J. Bergstralh, L. B. Woolner, M. A. Uhlenhopp, J. M. Piehler, D. R. Sanderson, P. E. Bernatz, D. E. Williams, W. F. Taylor, et al., "Roentgenographically Occult Lung Cancer. A Ten-Year Experience," Journal of Thoracic Cardiovascular Surgery, Vol. 86, No. 3, 1983, pp. 373-380.

[32] F. Hirsch, P. Bunn Jr., H. Kato and J. Mulshine, Eds., "Textbook of Prevention and Detection of Early Lung Cancer," Taylor and Francis, New York, 2006.

[33] A. M. McWilliams, J. R. Mayo, M. I. Ahn, S. L. MacDonald and S. C. Lam, "Lung Cancer Screening Using Multi-Slice Thin-Section Computed Tomography and Autfluorescence Bronchoscopy," Journal of Thoracic Oncology, Vol. 1, No. 1, 2006, pp. 61-68. doi:10.1097/01243894-200601000-00012 